\title{
Study Subject Radiography Report
}

National Cancer Institute

\section{Source}

National Cancer Institute. Study Subject Radiography Report. NCI Thesaurus. Code C115514.

Records pertaining to the findings from a study subject's radiographic images. 